\title{
Effect of Therapeutic Agents on Outcome of Different level of Progression of COVID-19 Infection in Pakistani Population
}

\author{
Shoukat Memon, Salman Imtiaz, Faiza Saeed, Ashar Alam, Beena Salman, \\ Javeria Chughtai, Shahzad Ahmed, and Sobia Tariq
}

\section{ABSTRACT}

\begin{abstract}
Background: Cytopathic effects of virus and cytokine release syndrome complicate acute respiratory distress syndrome and ultimately leads to multi-organ failure which can eventually culminate to mortality in COVID-19 patients. Many therapeutic agents have been tried from different aspects in desperation to control the unrestricted spread of virus, although the evidence of benefit was sparse.
\end{abstract}

Material and method: It is a retrospective cohort study of the treatment given to the patients admitted at Indus hospital Karachi from March 2020 to September 2020. In this study, we aim to evaluate therapeutic response of the treatment recommended in COVID-19 patients which included Methylprednisolone, Remdesivir, Tocilizumab and Hydroxychloroquine. We categorized the patients according to the CALL score (Comorbid, Age, Lymphocyte count, LDH) in to mild, moderate and at severe risk of progression of disease.

Results: Overall, out of 704 patients, $238(33.8 \%)$ patients died while 466(66.2\%) survived. Least deaths were observed in low-risk group $30(12.6 \%)$ as compared to intermediate group 98(41.2\%) and high risk patients $110(46.2 \%)$. In low, intermediate, and high risk groups, patients who didn't receive treatment showed better recovery $[61(95.3 \%)$ vs 90(76.9\%)], [59(75.6\%) vs 137(63.4)] and [31(63.3\%) vs 88(48.9\%)] respectively. Similarly, in Remdesivir group, the patients who did not receive the treatment showed good outcome $[(132(86.6 \%)$ vs15 $(62.5 \%)]$, [164 $(69.8 \%)$ vs $32(54.2 \%)]$ and $[103(56.3 \%)$ vs $16(34.8 \%)]$. In the same way Tocilizumab [136 $(86.6 \%)$ vs $15(62.5 \%)]$, [166 (72.5\%) vs $30(46.2 \%)]$ and $[103(57.9 \%)$ vs $16(31.4 \%)]$. Lastly, Hydroxychloroquine [133 $(86.4 \%)$ vs $18(66.7 \%)],[169(67.3 \%)$ vs27 $(62.8 \%)]$ and [102 (52\%) vs17 $(51.5 \%)]$. Over none of the treatment showed any beneficial effect on hospital stay and mortality.

Conclusion: Therapeutic option for treatment is limited and that these drugs as currently used should no longer be considered viable treatment options for COVID-19. There is need of research in developing new therapeutic options.

Keywords: COVID-19, Methylprednisolone, Remdesivir, tocilizumab, Hydroxychloroquine, COVID-19 treatment, Pakistan.
Published Online: June 28, 2021

ISSN: $2736-5476$

DOI: $10.24018 /$ ejclinicmed.2021.2.3.41

\section{S. Memon*}

Consultant Nephrologist, The Indus Health Network, Korangi Crossing Karachi, Pakistan.

(e-mail: shoukat.memon@ ${ }^{\circledR}$ tih.org.pk)

S. Imtiaz

Senior Consultant Nephrologist, The Indus Health Network, Korangi Crossing Karachi, Pakistan.

(e-mail: salman.imtiaz ${ }^{@}$ tih.org.pk)

F. Saeed

Consultant Nephrologist, The Indus Health Network, Korangi Crossing Karachi, Pakistan.

A. Alam

Senior Consultant Nephrologist, The Indus Health Network, Korangi Crossing Karachi, Pakistan.

B. Salman

Epidemiologist and Biostatician, Department of nephrology, The Indus Health Network, Korangi Crossing Karachi, Pakistan.

J. Chughtai

Registrar Nephrology, Department, The Indus Hospital, Korangi Crossing, Karachi, Pakistan.

S. Ahmed

Senior Resident nephrology, The Indus Health Network, Pakistan.

S. Tariq

Senior Resident Nephrology, The Indus health Network, Pakistan.

*Corresponding Author

\section{INTRODUCTION}

It has been one year since the emergence of COVID-19 pandemic, and the treatment of the disease is still speculative. Many therapeutic agents have been tried from different aspects, in desperation to rein the untrammelled spread of virus, although the evidence of benefit is sparse [1], [2]. There are at least three strategies evident by which course of the disease was challenged. Firstly, by inhibiting viral replication (Remdesivir, lopinavir), secondly by muting immune response to prevent manifestation such as cytokine release syndrome (glucocorticoids, Interlukin-6 blocker) and lastly by neutralizing the virus through passive immunity (Convalescent-phase plasma, monoclonal antibody) [3]. The 
evidence in support of any favourable effect by these therapies is not substantial and still under extensive research [4], [5].

There are many factors which affect the outcome of the treatment like at what stage of the disease the treatment was started, comorbid conditions, age, and immune status of the patients. [6]. There is need of more data in different populations to see the effect of the different pharmacological treatments used to treat COVID-19 patients with different severity and comorbid conditions. The objective of our study was to review the progression of disease in our patients and the effect of treatment on outcome.

\section{MATERIAL AND METHOD}

This is a retrospective observational cohort study of COVID-19 patients admitted in COVID-19 unit of Indus Hospital Karachi from 1st of March 2020 to 30th of Sep 2020. We included patients of all ages and the diagnosis of COVID19 was made by RT-PCR, performed through nasopharyngeal. Permission from the institutional ethical review committee was taken prior to conduction of study. Patient's clinical characteristic and laboratory parameters were acquired from the Health Management Information System (HMIS) record of the patients. Data was collected on a structured proforma which included variables like age, gender, comorbid conditions, disease progression, COVID specific treatment, hospital stay, lab parameters and outcome. Disease progression was calculated according to CALL (Comorbid, Age, Lymphocyte count, LDH) score (7) into low risk $(<10 \%$ progression risk, intermediate risk $(10 \%-40 \%$ progression risk) and high risk ( $>50 \%$ progression risk) (Table I).

\begin{tabular}{lccc}
\multicolumn{3}{c}{ TABLE I: CALCULATION OF CALL SCORE } \\
\hline & Call score predictor n $(\%)$ & $\begin{array}{c}\text { Call } \\
\text { score }\end{array}$ \\
\hline \multirow{2}{*}{ Age } & $<60$ years & $391(55.5)$ & 1 \\
& $\geq 60$ years & $313(44.5)$ & 3 \\
Comorbid & No & $188(26.7)$ & 1 \\
Lymphocyte & At least one & $516(73.3)$ & 4 \\
count & $>1 \times 109 / \mathrm{L}$ & $594(84.4)$ & 1 \\
& $>109 / \mathrm{L}$ & $110(15.6)$ & 3 \\
LDH & $\leq 25$ & $56(8)$ & 1 \\
& $251-500$ & $321(45.6)$ & 2 \\
& $>500$ & $327(46.4)$ & 3 \\
\hline
\end{tabular}

\section{A. Statistical Analysis}

The data was entered and analyzed in IBM SPSS version 21. Cleaning and coding of data was done prior to analysis. Frequencies and percentages were obtained for categorical variables, while mean \pm std was observed for continuous parameters. All continuous variables were categorized at the stage of analysis. Stratification of data was done according to three level of progression of disease and Chi square test was applied to observe any association between variables. Cox regression survival analysis was done to find the median hospital stay of patients according to the disease progression and treatment. The binary logistic regression analysis was executed to obtain odds ratio with $95 \%$ Confidence interval (CI) to predict death of the patients due to COVID-19. P value of $\leq 0.05$ was consider significant.

\section{RESULTS}

The description and division of study population according to CALL score is explained in Table I. Majority of our patients admitted with intermediate progression of disease 294 (41.8\%), patients' distribution according to the progression of disease is depicted in Fig. 1.

Overall, out of 704 patients, 238(33.8\%) patients died while $466(66.2 \%)$ survived. Least deaths were observed in low-risk group 30(12.6) as compared to intermediate group 98(41.2) and high risk patients 110(46.2) (Fig. 2). There were $539(76 \%)$ patients who received one or more than one form of treatment, while $165(23 \%)$ patients who didn't receive any form of COVID-19 specific treatment mentioned below. Methylprednisolone (MPS): In low risk group the patients who did not receive MPS showed better recovery as compared to those who received it [61(95.3\%) vs 90(76.9\%)]. Similar results were found in intermediate and high-risk groups in which the patients who did not received the MPS had more recovery than the patients who were treated with it $75.6 \%$ vs $63.4 \%$ and $63.3 \%$ vs $48.9 \%$ respectively (Table II).

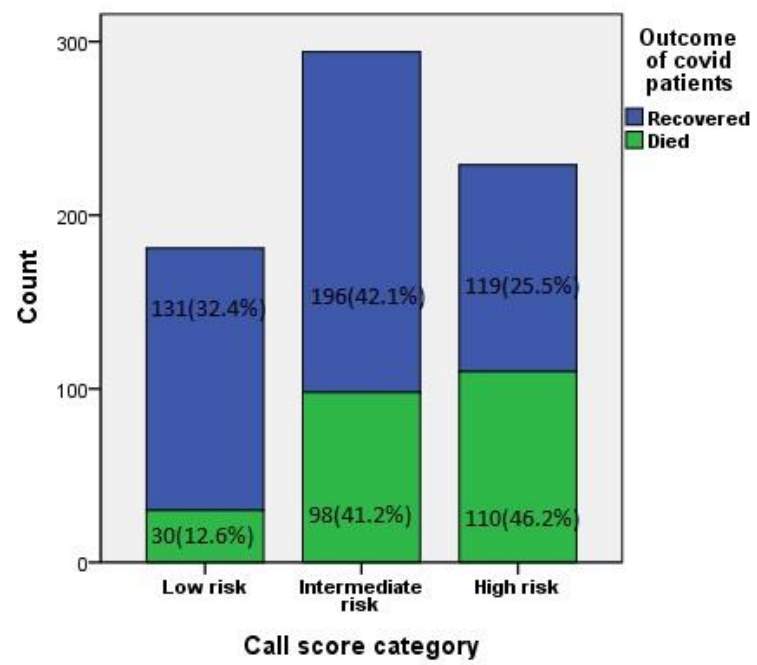

Fig. 2. Outcome of patients according to CALL.

\section{A. Methylprednisolone (MPS)}

In low-risk group, the patients who did not receive MPS showed better recovery as compared to those who received it [61(95.3\%) vs 90(76.9\%)]. Similar results were found in intermediate and high-risk groups in which the patients who did not received the MPS had more recovery than the patients who were treated with it $75.6 \%$ vs $63.4 \%$ and $63.3 \%$ vs $48.9 \%$, respectively (Table II).

\section{B. Remdesivir (RD)}

In low risk of disease progression, the RD was given to few patients and among them 19(76\%) patients recovered. Similarly, only $59(20.1 \%)$ of patients in intermediate group received the $\mathrm{RD}$ in which $32(54.2 \%)$ patients recovered, on the other hand, 164(69.8\%) patients recovered from untreated group. In addition to this when RD was given to high-risk group only $16(34.8 \%)$ patients recovered while majority of the patients died $30(65.2 \%)$, as compared to the patients who 
did not receive the treatment in which $103(56.3 \%)$ patients recovered and $80(43.7 \%)$ patients died (Table II).

TABLE II: ASSOCIATION OF TREATMENT WITH OUTCOME OF COVID-19, STRATIFIED BY CALL SCORE

\begin{tabular}{|c|c|c|c|c|c|c|}
\hline \multirow[b]{2}{*}{$\begin{array}{l}\text { Progression of disease } \\
\text { according to Call score }\end{array}$} & \multirow[b]{2}{*}{ Treatment } & & \multicolumn{2}{|c|}{ Outcome n (\%) } & \multirow[b]{2}{*}{ Total } & \multirow[b]{2}{*}{$P$ value } \\
\hline & & & $\begin{array}{l}\text { Recovered } \\
466(66.2 \%)\end{array}$ & $\begin{array}{c}\text { Died } \\
238(33.8 \%)\end{array}$ & & \\
\hline \multirow[t]{9}{*}{ Low risk 181(25.7\%) } & \multirow[t]{2}{*}{ Methylprednisolone } & Yes & $90(76.9)$ & $27(23.1)$ & $\begin{array}{c}117 \\
(64.6)\end{array}$ & \multirow{2}{*}{0.001} \\
\hline & & No & $61(95.3)$ & $3(4.7)$ & $64(35.4)$ & \\
\hline & \multirow{3}{*}{ Remdesivir } & Yes & $19(76)$ & $6(24)$ & $25(13.8)$ & \multirow{2}{*}{0.282} \\
\hline & & No & $132(86.6)$ & $24(15.4)$ & $25(13.8)$ & \\
\hline & & Yes & $15(62.5)$ & $9(37.5)$ & $24(13.3)$ & \multirow[b]{2}{*}{0.001} \\
\hline & Tocilizumab & No & $136(86.6)$ & $21(13.6)$ & $\begin{array}{c}154 \\
(85.1)\end{array}$ & \\
\hline & \multirow{2}{*}{ Hydroxychloroquine } & Yes & $18(66.7)$ & $9(33.3)$ & 27 (14.9) & \multirow[b]{2}{*}{0.001} \\
\hline & & No & $133(86.4)$ & $21(13.6)$ & $\begin{array}{c}154 \\
(85.1)\end{array}$ & \\
\hline & Total & & $151(32.4)$ & $30(12.6)$ & $181(25.7)$ & \multirow{4}{*}{0.05} \\
\hline \multirow[t]{9}{*}{$\begin{array}{c}\text { Intermediate risk } \\
294(41.8 \%)\end{array}$} & \multirow[t]{3}{*}{ Methylprednisolone } & Yes & $137(63.4)$ & 79 (36.6) & $\begin{array}{c}216 \\
(73.5)\end{array}$ & \\
\hline & & No & $59(75.6)$ & $19(24.4)$ & $78(26.5)$ & \\
\hline & & Yes & $32(54.2)$ & $22(45.8)$ & $59(20.1)$ & \\
\hline & Remdesivir & No & $164(69.8)$ & $71(16.6)$ & $\begin{array}{c}239 \\
(79.9)\end{array}$ & \multirow[t]{2}{*}{0.023} \\
\hline & \multirow[b]{2}{*}{ Tocilizumab } & Yes & $30(46.2)$ & $35(53.8)$ & $65(22.1)$ & \\
\hline & & No & $166(72.5)$ & $63(27.5)$ & $\begin{array}{c}229 \\
(77.9)\end{array}$ & $<0.001$ \\
\hline & \multirow[b]{2}{*}{ Hydroxychloroquine } & Yes & $27(62.8)$ & $16(37.2)$ & $43(14.6)$ & \multirow[b]{2}{*}{0.56} \\
\hline & & No & $169(67.3)$ & $82(32.7)$ & $\begin{array}{c}251 \\
(85.4)\end{array}$ & \\
\hline & Total & & $196(42.1)$ & $98(41.2)$ & $294(41.8)$ & \\
\hline \multirow[t]{9}{*}{ High risk $229(32.5 \%)$} & \multirow[t]{3}{*}{ Methylprednisolone } & Yes & $88(48.9)$ & $92(51.1)$ & $\begin{array}{c}180 \\
(78.6)\end{array}$ & \multirow[t]{3}{*}{0.074} \\
\hline & & No & $31(63.3)$ & $18(36.9)$ & $49(21.4)$ & \\
\hline & & Yes & $16(34.8)$ & $30(65.2)$ & $46(20.1)$ & \\
\hline & \multirow[t]{2}{*}{ Remdesivir } & No & $103(56.3)$ & $80(43.7)$ & $\begin{array}{c}183 \\
(79.9)\end{array}$ & \multirow[t]{2}{*}{0.009} \\
\hline & & Yes & $16(31.4)$ & $35(68.6)$ & $51(22.3)$ & \\
\hline & \multirow[t]{2}{*}{ Tocilizumab } & No & $103(57.9)$ & $75(42.1)$ & $\begin{array}{c}178 \\
(77.7)\end{array}$ & \multirow[t]{2}{*}{0.001} \\
\hline & & Yes & $17(51.5)$ & $16(48.5)$ & $33(14.4)$ & \\
\hline & Hydroxychloroquine & No & $102(52)$ & $94(48)$ & $\begin{array}{c}196 \\
(85.6)\end{array}$ & 0.955 \\
\hline & Total & & $119(25.5)$ & $110(46.2)$ & $229(32.5)$ & \\
\hline
\end{tabular}

\section{Tocilizumab: (TOCI)}

Same as the Remdesivir, the TOCI also given to a smaller number of patients in low-risk group and among them $15(62.5 \%)$ patients recovered, while the patients who did not received the TOCI $136(86.6 \%)$ recovered. Likewise, in intermediate group the patients who did not receive the TOCI, recovered more than the patients who received it $166(72.5 \%)$ vs $30(46.2 \%)$. Consistently, the TOCI had negative outcome in the high-risk group, in which $51(22.3 \%)$ patients received TOCI and among them $35(68.6 \%)$ patients died while only $16(31.4 \%)$ recovered as compared to non-receivers in which $103(57.9 \%)$ patients recovered and $75(42.1 \%)$ patients died (Table II).

\section{Hydroxychloroquine (HCQ)}

Only $27(14.9 \%)$ patients who were in low-risk group treated with HCQ in which $18(66.7 \%)$ recovered while among the patients who were not treated with HCQ $133(86.4 \%)$ patients recovered. In intermediate group the outcome of both patients who were treated or not treated with HCQ was almost the same [27(62.8\%) vs $169(67.3 \%)]$ respectively. In the same way, recovery in patients with high risk of disease progression was the same when treated with HCQ or not $17(51.5 \%)$ and 102(52\%) (Table II).

Survival analysis showed that patients who had mild disease and did not receive any covid specific treatment had least hospital stay as compared with other patients. The median stay was of 5 days $(95 \% \mathrm{CI} 4.4-5.6)$. On the other hand, the patients with high risk of progression of disease and received multiple drugs like MPS, RD and TOCI to control the disease during hospital stay suffered longest stay in hospital, their median stay was 19 days (95\% ci $12.9-25.1$ ) (Fig. 3 and Table III).

We also observed the individual effect of disease progression and treatment on survival and found that the patients with high risk of progression died 4.7 times more than the patients with low-risk progression of the disease. Similarly, patients who needed MPS or any combination along with MPS died more than the patients who did not need immunosuppressions or antiviral treatment. The worst outcome was observed in those patients who received combination of MPS, RD and TOCI as they died 8 times more than the patients with no treatment (Table III). 
TABLE III: MEDIAN HOSPITAL STAY OF PATIENTS ACCORDING TO DISEASE SEVERITY AND TREATMENT, AND THEIR ASSOCIATION WITH DEATH

\begin{tabular}{|c|c|c|c|c|c|}
\hline $\begin{array}{c}\text { Disease severity } \\
\text { and Treatment }\end{array}$ & $\begin{array}{c}\text { Median } \\
\text { hospital } \\
\text { stay in } \\
\text { days }\end{array}$ & $\begin{array}{l}95 \% \text { CI } \\
\text { Lower- } \\
\text { Upper }\end{array}$ & $\begin{array}{l}\text { Odds } \\
\text { ratio }\end{array}$ & $\begin{array}{l}95 \% \\
\text { CI } \\
\text { Lower- } \\
\text { Upper }\end{array}$ & $\mathrm{p}$ value \\
\hline Overall & 7 & $6.6-7.4$ & - & - & - \\
\hline Low risk & 5 & $4.4-5.6$ & - & - & - \\
\hline Intermediate risk & 7 & $6.4-7.6$ & 2.5 & $1.6-4$ & $<0.001$ \\
\hline $\begin{array}{l}\text { High risk } \\
\text { No }\end{array}$ & 11 & $9.3-12.7$ & 4.7 & $2.9-7.4$ & $<0.001$ \\
\hline $\begin{array}{c}\text { Immunosuppressive } \\
\text { treatment }\end{array}$ & 5 & 4.4-5.6 & 1 & - & - \\
\hline Methylprednisolone & 7 & $6.4-7.6$ & 2.5 & $1.6-4.1$ & $<0.001$ \\
\hline $\begin{array}{l}\text { Methylprednisolone } \\
\text { +Remdesivir }\end{array}$ & 9 & $7-11.1$ & 3.5 & $1.8-6.6$ & $<0.001$ \\
\hline $\begin{array}{l}\text { Methylprednisolone } \\
\text { +Tocilizumab }\end{array}$ & 14 & $10.9-17.1$ & 6.3 & $\begin{array}{l}3.5- \\
11.6\end{array}$ & $<0.001$ \\
\hline $\begin{array}{c}\text { Methylprednisolone } \\
\text { +Remdesivir+ } \\
\text { Tocilizumab }\end{array}$ & 19 & $12.9-25.1$ & 8 & 4-15.5 & $<0.001$ \\
\hline
\end{tabular}

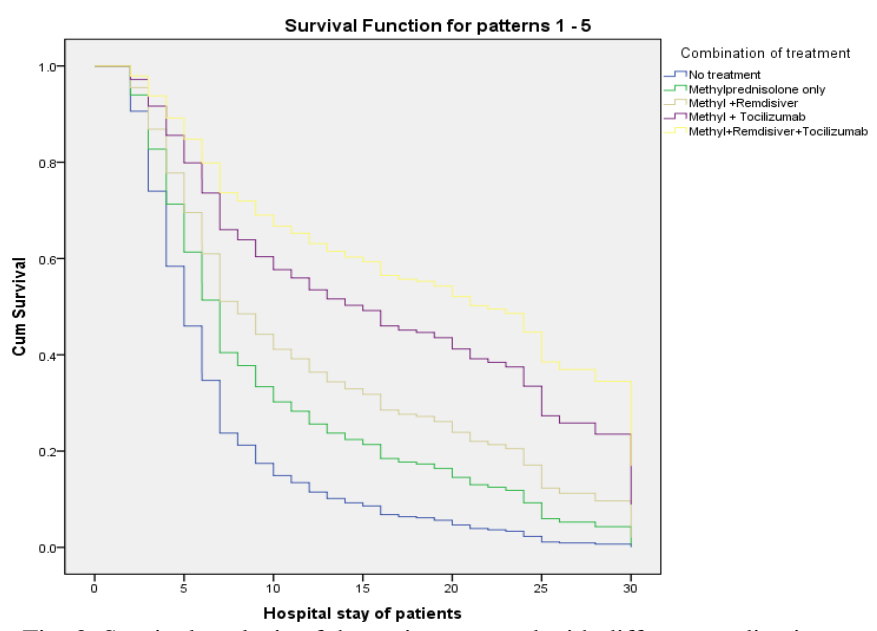

Fig. 3. Survival analysis of the patients treated with different medications.

\section{DISCUSSION}

This is the first study from this country which evaluated the effects of almost all important therapeutic agents which are still in the armamentarium of COVID-19 treatment. It is dismaying that almost one year has passed and we are still in search of a breakthrough treatment of this fatal disease. The impression that we got from this data is that these medications need to be identified with their specific place with the patients in whom they have the best effect on.

In our study steroids did not show any beneficial effect on hospital stay and on survival as well. Steroids have been linked with reduced clearance of virus and increased viral load in both Middle East respiratory and SARS Cov pneumonia and caused a compromised outcome in influenza pneumonia [8], [9]. On the other hand in non-COVID-19 pneumonia with ARDS, it showed contradictory results. [10], [11]. In COVID-19, steroids showed conflicting results, for example, in The CoDEX Randomized Clinical Trial comprises of 299 patients, comparing dexamethasone vs placebo in moderate to severe ARDS, investigators found statistically significant increase in the number of ventilatorfree days (days alive and free of mechanical ventilation) over 28 days, with the use of intravenous dexamethasone plus standard care compared with standard care alone [12]. On the contrary, in another multicentred randomized double-blind sequential trial conducted in France, patients were randomized to receive low-dose hydrocortisone vs placebo. The investigators concluded that the hydrocortisone did not significantly reduce treatment failure (defined as death or persistent respiratory support) at day 21 . Although, the study was terminated early and likely was underpowered to find a statistically and clinically important difference in the primary outcome [13].

$\mathrm{RD}$ entered into the treatment regimen after authorization of its emergency use granted by US Food and Drug Administration as well by European medicine agency for the management of COVID-19 in patients 12 years of age or older with pneumonia who require supplemental oxygen [14], [15]. The effect of RD was also very marginal in our patients, and it did not show any benefit in improving the survival and hospital stay. Although, in other studies it showed some benefit in time to recover from ventilator. For instance, in a large double blind RD placebo-controlled ACCT-1 trial, RD was found to be superior to placebo in shortening the time to recover in severe COVID-19 as compared with those receiving placebo which was 11 days vs 15 days [16]. In another randomized open label trial assigned to $1: 1$ ratio to receive $\mathrm{RD}$ for either 5 to 10 days, it was concluded that the patients with severe COVID-19 who did not require mechanical ventilation did not show any significant difference between 5 days and 10 days course [17]. TOCI, which is an interleukin-6 receptor monoclonal antibody, was approved by FDA for the treatment of cytokine release syndrome. Interleukin-6 levels are correlated with viral load, disease severity and prognosis. In a large observational cohort, Gupta and Wang found lower in-hospital mortality in patients treated with TOCI in first 2 days of ICU admission compared with patients whose treatment did not include early use of TOCI [18]. Similarly, Jordan et al also found a beneficial effect of TOCI in reducing inflammation, oxygen requirement, vasopressor support and mortality [19]. Our results were very disappointing with TOCI as no retardation in the progress of disease was found in any group. Rather, we experienced that the patients who received TOCI developed more hospital acquired infections and bacterial sepsis. In this connection, we also want to mention (although not included in this study) that in a subgroup of the patients who developed acute kidney injury and received TOCI succumbed to worse outcome that compared patients who received TOCI and standard care, the investigators found that the patients who received TOCI showed no benefit on disease progression as compared with standard care [21]. In another randomized, double blind placebo-controlled trial involving confirmed severe COVID disease, the treatment assigned was standard care plus TOCI and standard care plus placebo. The investigators concluded that TOCI was not effective for preventing intubation or death in moderately ill hospitalized patients with COVID-19 [22].

However, in a randomized control trial comparing with usual care and usual care alone in French population, Hermine et al found no difference on the day 28 mortality and was neither able to reduce WHO-CPS score on day 4 [20]. Similarly in a prospective, open label, randomized Italian trial

Lastly, the Hydroxychloroquine was used in a smaller number of patients in our population but its effect was neutral 
as its effect was same on the outcome in all risk groups whether it was used or not, although its use was associated with cardiac rhythm abnormalities. Recently published interim WHO Solidarity trial showed similar results.

There are few limitations of the study. This is an observational study in nature and the data was collected retrospectively, although size of the population is adequate as no other data is published with this number from this area. Our population is different from the western population in respect of median age, socioeconomical status, health care structure and provision. The epidemiology and demography of COVID-19 is different in this population. Therefore, despite the presence of the factors which were thought to deteriorate the outcome of the disease in this population, the mortality was not as high as we are still observing in the western population [23]. We have the same observation of our study which the editorial writers of Solidarity trial have "Viewed collectively with previous studies, the Solidarity trial sends the clear message that these drugs as currently used should no longer be considered viable treatment options for COVID-19” [24].

\section{CONCLUSION}

Therapeutic options for treatment are limited and that these drugs as currently used should no longer be considered viable treatment options for COVID-19. There is need of research in developing new therapeutic options.

\section{ACKNOWLEDGEMENT}

We highly appreciate the service of Dr. Jahanzeb Khan and Ms. Yumna Maheen who helped us in collecting the data and review the manuscript, respectively.

\section{REFERENCES}

[1] Liuzzo G, Patrono C. Re-purposed antiviral drugs without a purpose in COVID-19: a valuable lesson for clinicians. European Heart Journal. 2021 Feb 11.

[2] Huang E, Jordan SC. Tocilizumab for Covid-19-The Ongoing Search for Effective Therapies. n engl j med2020. 383;24 :2387-2388.

[3] Chen PL, Lee NY, Cia CT, Ko WC, Hsueh PR. A Review of Treatment of Coronavirus Disease 2019 (COVID-19): Therapeutic Repurposing and Unmet Clinical Needs. Frontiers in pharmacology. 2020;11.

[4] WHO Solidarity Trial Consortium. Repurposed antiviral drugs for Covid-19 - interim WHO Solidarity trial results. N Engl J Med 2021;384:497-511.

[5] Gautret P, Lagier JC, Parola P, Meddeb L, Mailhe M, Doudier B, Courjon J, Giordanengo V, Vieira VE, Dupont HT, Honoré S. Hydroxychloroquine and azithromycin as a treatment of COVID-19: results of an open-label non-randomized clinical trial. International journal of antimicrobial agents. $2020 \mathrm{Jul} \mathrm{1;56(1):105949.}$

[6] Chidambaram V, Tun NL, Haque WZ, Majella MG, Sivakumar RK, Kumar A, Hsu AT, Ishak IA, Nur AA, Ayeh SK, Salia EL. Factors associated with disease severity and mortality among patients with COVID-19: A systematic review and meta-analysis. PloS one. 2020 Nov 18;15(11):e0241541.

[7] Ji D, Zhang D, Xu J, Chen Z, Yang T, Zhao P, Chen G, Cheng G, Wang Y, Bi J, Tan L. Prediction for progression risk in patients with COVID19 pneumonia: the CALL score. Clinical Infectious Diseases. 2020 Sep 15;71(6):1393-9.

[8] Arabi YM, Mandourah Y, Al-Hameed F, et al; Saudi Critical Care Trial Group. Corticosteroid Therapy for critically ill patients with Middle East respiratory syndrome. Am J Respir Crit Care Med. 2018;197(6):757-767. doi:10.1164/rccm.201706- 1172OC.
[9] Lee N, Allen Chan KC, Hui DS, et al. Effects of early corticosteroid treatment on plasma SARS-associated Coronavirus RNA concentrations in adult patients.J Clin Virol. 2004;31(4):304-309. doi:10.1016/j.jcv.2004.07.006.

[10] Villar J, Ferrando C, Martínez D, et al; Dexamethasone in ARDS Network. Dexamethasone treatment for the acute respiratory distress syndrome: a multicentre, randomised controlled trial. Lancet Respir Med. 2020;8(3):267-276. doi:10. 1016/S2213-2600(19)30417-5.

[11] Steinberg KP, Hudson LD, Goodman RB, et al; National Heart, Lung, and Blood Institute Acute Respiratory Distress Syndrome (ARDS) Clinical Trials Network. Efficacy and safety of corticosteroids for persistent acute respiratory distress syndrome. N Engl J Med. 2006;354(16): 1671-1684. doi:10.1056/NEJMoa051693.

[12] Tomazini BM et al. Effect of dexamethasone on days alive and ventilator-free in patients with moderate or severe acute respiratory distress syndrome and COVID-19: The CoDEX randomized clinical trial. JAMA 2020 Sep 2; [e-pub]

[13] Dequin PF, Heming N, Meziani F, Plantefève G, Voiriot G, Badié J, François B, Aubron C, Ricard JD, Ehrmann S, Jouan Y. CAPE COVID Trial Group and the CRICS-TriGGERSep Network. Effect of hydrocortisone on 21-day mortality or respiratory support among critically ill patients with COVID-19: a randomized clinical trial JAMA. 2020 Oct 6;324(13):1-9.

[14] US Food and Drug Administration. Coronavirus (COVID-19) update: FDA issues emergency use authorization for potential COVID-19 treatment. Published May 1, 2020. Accessed August 10, 2020.

[15] European Medicines Agency. First COVID-19 treatment recommended for EU authorization. PublishedJune25, 2020. Accessed August 10, 2020

[16] Beigel JH, Tomashek KM, Dodd LE, Mehta AK, Zingman BS, Kalil AC, Hohmann E, Chu HY, Luetkemeyer A, Kline S, de Castilla DL. Remdesivir for the treatment of Covid-19-preliminary report. The New England journal of medicine. 2020 May 22.

[17] Goldman JD, Lye DCB, Hui DS, et al; GS-US-540-5773 Investigators. Remdesivir for 5 or 10 days in patients with severe Covid-19. N Engl J Med. Published online May 27, 2020. doi:10.1056/ NEJMoa2015301.

[18] Gupta S, Wang W, Hayek SS, Chan L, Mathews KS, Melamed ML, Brenner SK, Leonberg-Yoo A, Schenck EJ, Radbel J, Reiser J. Association between early treatment with tocilizumab and mortality among critically ill patients with COVID-19. JAMA internal medicine. 2021 Jan 1;181(1):41-51

[19] Jordan SC, Zakowski P, Tran HP, Smith EA, Gaultier C, Marks G, Zabner R, Lowenstein H, Oft J, Bluen B, Le C. Compassionate use of tocilizumab for treatment of SARS-CoV-2 pneumonia. Clinical Infectious Diseases. 2020 Jun 23.

[20] Hermine O, Mariette X, Tharaux PL, Resche-Rigon M, Porcher R, Ravaud P, Bureau S, Dougados M, Tibi A, Azoulay E, Cadranel J. Effect of tocilizumab vs usual care in adults hospitalized with COVID19 and moderate or severe pneumonia: a randomized clinical trial JAMA internal medicine. 2021 Jan 1;181(1):32-40.

[21] Salvarani C, Dolci G, Massari M, Merlo DF, Cavuto S, Savoldi L, Bruzzi $\mathrm{P}$, Boni F, Braglia L, Turrà C, Ballerini PF. Effect of tocilizumab vs standard care on clinical worsening in patients hospitalized with COVID-19 pneumonia: a randomized clinical trial JAMA internal medicine. 2021 Jan 1;181(1):24-31.

[22] Stone JH, Frigault MJ, Serling-Boyd NJ, Fernandes AD, Harvey L, Foulkes AS, Horick NK, Healy BC, Shah R, Bensaci AM, Woolley AE. Efficacy of tocilizumab in patients hospitalized with Covid-19. New England Journal of Medicine. 2020 Dec 10;383(24):2333-44

[23] Atif M, Malik I. Why is Pakistan vulnerable to COVID-19 associated morbidity and mortality? A scoping review. The International journal of health planning and management. 2020 Sep;35(5):1041-54.

[24] Harrington DP, Baden LR, Hogan JW. A Large, Simple Trial Leading to Complex Questions. $2021 \mathrm{n}$ engl j med 384;6:576-577.

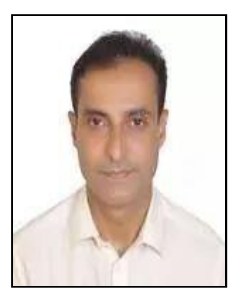

Shoukat Memon is currently working as consultant Nephrologist in the Indus Health network Karachi, Pakistan. He earned his Fellowship degree in field of nephrology in 2013 from College of Physician and Surgeon, then joined as senior lecturer at Sindh Institute of Urology and transplantation, Karach Pakistan where he completed this nephrology residency also. He moved to Indus health network since 2014.This nephrology program was of three years which was preceded by 2 year internal medicine training which he did in Liaquat University of medical and health sciences Jamshoro. He is member of Pakistan Society of Nephrology. Apart from that $\mathrm{He}$ fulfils responsibilities in training residents in nephrology which is associated with College of physician and surgeon, Pakistan. 